\title{
Effect of Processing Parameters on Hot Deformation Behaviour and Microstructural Evolution of PM Ti-5553 Alloy at a Moderate-high Strain Rate
}

\author{
Qinyang Zhao ${ }^{a}$, Fei Yang ${ }^{*} *$, Rob Torrens ${ }^{a}$, Leandro Bolzoni ${ }^{a}$ \\ ${ }^{a}$ Waikato Centre for Advanced Materials, School of Engineering, University of Waikato, Hamilton, New \\ Zealand
}

Received: November 19, 2018; Revised: February 05, 2019; Accepted: April 29, 2019

\begin{abstract}
Isothermal compression tests of Ti-5553 (Ti-5Al-5V-5Mo-3Cr) alloy, produced by a fast consolidation approach from blended elemental powder mixture, were performed on a Gleeble ${ }^{\circledR} 3800$ thermal-physical simulator to investigate its hot deformation behaviour. The samples were compressed in a wide temperature range from $700{ }^{\circ} \mathrm{C}$ to $1150{ }^{\circ} \mathrm{C}$ and a moderate-high strain rate of $1 \mathrm{~s}^{-1}$, with the sample deformation degree of $30 \%, 50 \%$ and $70 \%$, respectively. Flow instability occurred when the deformation temperature was less than $900{ }^{\circ} \mathrm{C}$. Dynamic recovery (DRV) accompanied by dynamic recrystallization (DRX) become the dominated mechanisms at the medium temperature range between $900{ }^{\circ} \mathrm{C}$ and $1000{ }^{\circ} \mathrm{C}$, while almost only DRV features could be observed at high temperature (1050 $\left.{ }^{\circ} \mathrm{C} \sim 1150{ }^{\circ} \mathrm{C}\right)$. Moreover, $\alpha$ phase globalization could be identified in the alloy deformed in $(\alpha+\beta)$ region. DRV, DRX, $\alpha$ globalization and the transformation of $\alpha$ to $\beta$ phase were promoted with the increasing deformation degree.
\end{abstract}

Keywords: Powder metallurgy, Ti-5553 alloy, Hot deformation behaviour, Microstructural evolution, Deformation mechanism.

\section{Introduction}

The alloy of Ti-5553 (Ti-5Al-5V-5Mo-3Cr) has become attractive material extensively for aerospace and marine industry field as it low density, ultra-high strength, good ductility and excellent hardenability ${ }^{1,2}$. The thick forging parts of the alloy have been successfully used in the landing gears and the wings' covering of the Boeing and Airbus aircrafts ${ }^{3,4}$. Although titanium alloys are becoming the ideal choices of the materials for some high-performance applications, the relatively high cost limits their widespread use coming from the melting of the raw material, hot processing and subsequent machining.

Using raw powders to prepare the titanium alloy products instead of conventional melting and casting is proved as a feasible method with the economic benefits. Powder metallurgy (PM) titanium alloys parts can be produced through hot isostatic pressing, vacuum sintering and selective melting with qualified properties and refined microstructures ${ }^{5,6}$. In order to reduce the cost further and shorten the manufacturing period, fast consolidation approaches have been developed by the researchers like power forging and hot pressing 7,8 .

Near-beta titanium alloys like Ti-5553 are even more hard to process among the titanium alloys and always need the hot processing for several steps, leading to the significant growth of the producing cost. Moreover, the quality of Ti-5553 alloy products is extremely dependent on the hot working variables which can influence the microstructural evolution significantly ${ }^{9}$. The deformation mechanisms like

*email:fei.yang@waikato.ac.nz dynamic recrystallization (DRX) and dynamic recovery (DRV) can refine and homogenize microstructure and they are always regarded as the optimal softening mechanisms. Therefore, it becomes important to study the effect of the hot working parameters on the hot deformation behaviour of the Ti-5553 alloy for the optimization of the microstructures and properties. Some previous researches have been conducted to investigate the effect of the deformation parameters on the behaviour of titanium alloys.

Some previous researches have been conducted to investigate the hot deformation behaviour and the effects of the hot processing parameters on titanium alloys. Warchomicka et al. ${ }^{10}$ studied the hot deformation behaviour of Ti-5Al-5Mo-5V-3Cr-1 $\mathrm{Zr}$ alloy using various deformation parameters. They found $\beta$-restoration with elongation and rotation of $\alpha$ grains were obvious in the $(\alpha+\beta)$ region, DRX processes were mainly observed in the deformation in single $\beta$ region deformation strain, while DRV was the dominated mechanism at the wide temperature range in both $(\alpha+\beta)$ and single $\beta$ regions. Seshacharyulu et al. ${ }^{11}$ reported the changing regulation of deformation mechanism with varying deformation parameters of commercial grade Ti-6Al-4V alloy. The material suffered from cracking and adiabatic shear bands at low-temperature deformation lower than $900{ }^{\circ} \mathrm{C}$, phase globalization and lamellae kinking took effects at the intermediate temperature between 900 ${ }^{\circ} \mathrm{C}$ and $1000{ }^{\circ} \mathrm{C}$, and the high-temperature deformation is primarily dominated by DRX. Fan et al. ${ }^{12}$ investigated the hot deformation behaviour of Ti-7Mo-3Nb-3Cr-3Al alloy, and revealed the effects of deformation temperature on the flow behaviour and microstructure evolution. The effects of 
deformation parameters on the hot deformation behaviour of Ti-25V-15Cr-0.3Si titanium alloy were reported by Zhu et al. ${ }^{13}$ They disclosed that the DRX fraction increased with increasing the deformation temperature.

Whereas, there is still limited works carried out to study the effect of the hot working parameters on the hot deformation behaviour of PM titanium alloys, leading to the insufficient information for the industries to conduct the optimal hot processing of PM titanium alloy. This present work investigated the influence of the deformation parameters including temperature and deformation degree on the hot deformation behaviour of a PM Ti-5553 alloy obtained through fast consolidated techniques at a moderate-high strain rate of $1 \mathrm{~s}^{-1}$, the flow softening and the microstructural evolution during the deformation have been studied and discussed.

\section{Experimental Details}

The as-consolidated PM Ti-5553 (Ti-4.99Al-4.93V4.94Mo-2.90Cr-0.05Fe-0.36O) alloy studied in this work is prepared using the raw powders as: hydride-dehydrided (HDH) titanium powder (-200 mesh, purity: 99.6\%), Al powder (purity: 99.9\%), Al35-V65, Al15-Mo85 and Al30Cr70 (wt\%) master alloy powders $(-75 \mu \mathrm{m}$, commercial purity) supplied by Dalian Rongde Company, PR China. The powder mixture the was warm compressed (400 MPa, 250 ${ }^{\circ} \mathrm{C}$, in air) into green powder compact (56 mm in diameter and $52 \mathrm{~mm}$ in height) after the mixing for $1.5 \mathrm{~h}$ at the speed of $60 \mathrm{rpm}$ in a $\mathrm{V}$-shape blender. Afterwards, the green powder compact was heated up rapidly in an induction furnace to $1250^{\circ} \mathrm{C} \sim 1300^{\circ} \mathrm{C}$ and held for $10 \mathrm{~min}$, followed by uniaxial hot pressing into cylindrical alloy billet $(58 \mathrm{~mm}$ in diameter and $42 \mathrm{~mm}$ high) under $400 \mathrm{MPa}$ pressure and reach the relative density about $98 \%$ (The relative density of the alloy was determined by the Archimedes principle, the weight measurement were done in water and air using the standard of ASTM B962). A 100-ton hydraulic press was utilized to perform warm compaction and hot pressing. The rapid heating, hot pressing and cooling processes were operated in a flow argon atmosphere protective chamber had the oxygen content of below $200 \mathrm{ppm}$ to avoid oxidation. The $\beta$ phase transus temperature is measured as $975^{\circ} \mathrm{C}$ according to the metallographic results after heat treatment and quenching. Fig. 1 shows the initial microstructure of the PM Ti-5553 alloy, primary fine $\beta$ phase matrix with the average grain size of $100 \mu \mathrm{m}$, a small number of precipitations (inhomogeneous and agglomerative) and some visible residual pores can be easily identified.

Gleeble ${ }^{\circledR}$ 3800-GTC thermal physical simulator was used to conduct the hot compression tests at the temperature range of $700{ }^{\circ} \mathrm{C}$ to $1150{ }^{\circ} \mathrm{C}$ at the strain rate of $1 \mathrm{~s}^{-1}$. The cylinder specimens were produced from the alloy billets by wire cut and the following machining to the target size of $10 \mathrm{~mm}$ diameter and $15 \mathrm{~mm}$ height. The specimens were

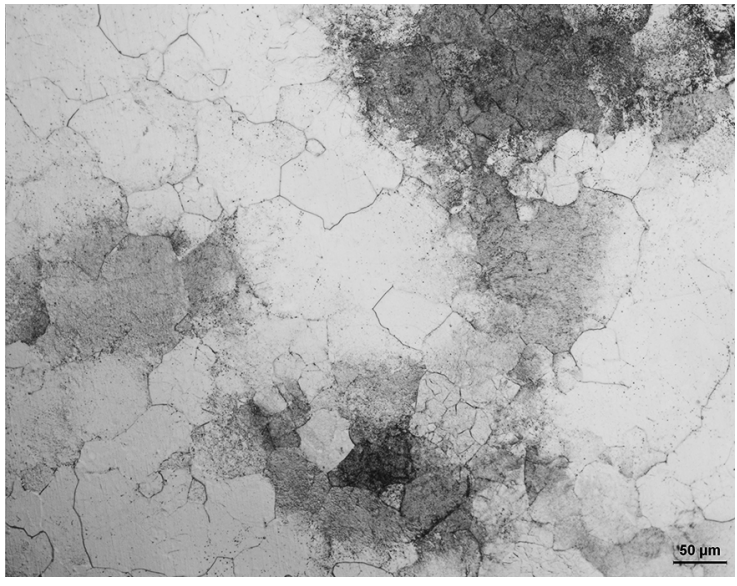

Figure 1. Optical image showing the origin microstructure of asconsolidated PM Ti-5553 alloy

heated up to the preconcerted temperatures at the rate of 10 ${ }^{\circ} \mathrm{C} / \mathrm{s}$ and soak $4 \mathrm{~min}$ to ensure the homogeneous temperature distribution in the specimen, after which, the specimens were isothermally compressed to different height reductions in vacuum. After the deformation, the specimens were cooled rapidly in water to retain the deformed microstructure. Graphite foils and Tantalum sheets were used to improve the system conductivity and reduce the friction between the specimens and the die.

The phase constitutions of the deformed samples were analysed by X-ray diffraction (XRD) with a Bruker D8 Advanced X-ray diffractometer equipped with a $\mathrm{Cu} \mathrm{K} \alpha$ radiation source $(\lambda=0.154157 \mathrm{~nm})$. The microstructure characterizations were performed using optical microscopy (OM, OLYMPUS/PMG3), and scanning electron microscopy (SEM, JSM-6460). The metallographic samples were prepared through grinding, polishing and Kroll's reagent etching (10 $\mathrm{ml} \mathrm{HF}, 20 \mathrm{ml} \mathrm{HNO}_{3}$ and $70 \mathrm{ml} \mathrm{H}_{2} \mathrm{O}$ ).

\section{Results and Discussion}

\subsection{True stress-strain curves}

Fig. 2 displays some related true stress-strain curves of the PM Ti-5553 alloy deformed at $1 \mathrm{~s}^{-1}$ in the temperature range of $700{ }^{\circ} \mathrm{C}$ to $1150{ }^{\circ} \mathrm{C}$. It is obvious that all the curves suggest similar trends at the beginning of the deformation with a dramatic increase of the stress to the peak values followed by different flow softening mode to the steady-state stages. For the specimens deformed at the temperatures lower than $800{ }^{\circ} \mathrm{C}$, the constant softening can be seen after the stress peaks, indicating the occurrence of strong flow softening like flow localization and cracking ${ }^{12-15}$. Slight drops after the peak stress and subsequent gradually decreasing of the curves are observed for the condition of $900{ }^{\circ} \mathrm{C}, 950{ }^{\circ} \mathrm{C}$ and $1000{ }^{\circ} \mathrm{C}$, these typical features suggest the flow softening may be controlled by DRX. In terms of the deformation conducted 
at a high temperature over $1050{ }^{\circ} \mathrm{C}$, the flow stress is kept steady after the peak stress, which means the dominated softening mechanism could be DRV with high possibility. Moreover, it can not be ignored that considerable oscillation of some the curves can be found in some conditions, which can be ascribed to DRX or flow instability and has been observed in some other titanium alloys ${ }^{12}$.

Moreover, the flow stress shows a high sensitivity of the deformation temperature, as shown in Fig. 3a. The peak stress is reducing obviously with increasing the temperature, as the deformation becomes easier due to more thermal activation effect and the enhanced diffusion process. In addition, the flow softening values (using the deviation of peak stress and the steady-state stress at the strain of 1.0) also illustrate a constantreduction trend at the temperature range low than beta transus, while the flow softening keeps at a low and stable stage after the beta transus (Fig. 3b). These means the softening mechanism is different before and after the $\alpha \rightarrow \beta$ phase transformation. As it can be realized that it is difficult and to determine the deformation mechanisms only rely on the flow behaviour, so the microstructural evolution characterizations are necessary to be conducted for further discussions.

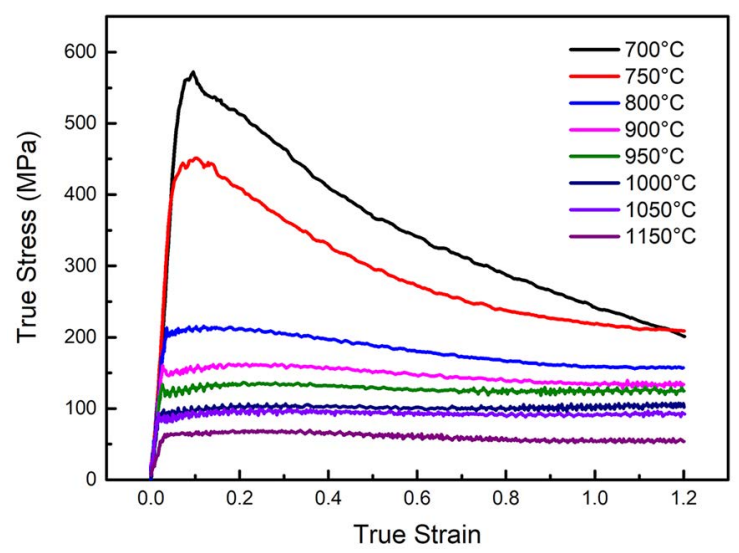

Figure 2. True stress-stain curves of as-consolidated PM Ti-5553 alloy at $1 \mathrm{~s}^{-1}$ and various temperatures

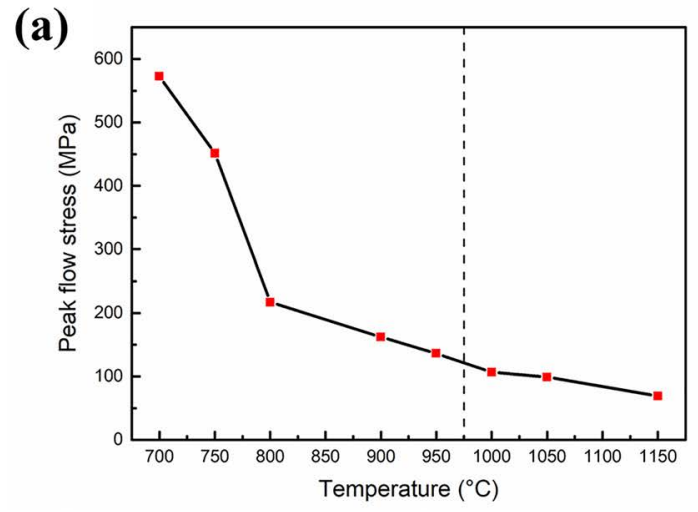

\subsection{Microstructure evolution at $(\alpha+\beta)$ region}

Fig. 4 displays the optical microstructures and SEM characteristics of deformed PM Ti-5553 alloy subjected to various temperatures and strain at $1 \mathrm{~s}^{-1}$ in $(\alpha+\beta)$ region. As can be identified in Fig. $4 \mathrm{a}$ of $700^{\circ} \mathrm{C}$ specimen, the microstructure consists with a large amount of $\alpha$ precipitation band $\beta$ matrix, the grain boundaries are difficult to be observed. Meanwhile, the specimen displays a serious flow localization band with inhomogeneous deformation in a macroscopic view, as seen in Fig. 4b. The microstructure (Fig. 4c) and macroscopic view (Fig. 4d) of $800^{\circ} \mathrm{C}$ specimen show the similar characteristics with $700{ }^{\circ} \mathrm{C}$ specimen, but less $\alpha$ precipitation bands and slighter flow localization situation. These results indicate that the dominated softening mechanism at $700{ }^{\circ} \mathrm{C}$ and $800{ }^{\circ} \mathrm{C}$ is flow localization and dynamic $\alpha$ precipitation, and flow localization degree become slighter as increasing the deformation temperature. The flow localization band is generated based on the local temperature rise attribute to the short deformation time and the poor thermal conductivity of titanium alloys ${ }^{16}$. When the temperature increase to the relatively higher value, the degree of the localized flow will reduce as the lower local temperature rise.

When it comes to the deformation of $900{ }^{\circ} \mathrm{C}$ and $30 \%$ height reduction specimen, the slightly elongated grains with some areas full of $\alpha$ precipitates can be clearly found in Fig. 4e. Whereas, when the deformation degree increase to $70 \%$ at $900{ }^{\circ} \mathrm{C}$ (Fig. 4f), the grains are obviously elongated along the direction vertical to compression direction with serrate grain boundaries, and the amount and morphology of $\alpha$ precipitates also become less and band-shaped. The phase constitution changes of $900{ }^{\circ} \mathrm{C}$ specimens for different deformation degrees can also be confirmed by the XRD tests. As is shown in Fig. 5a and b, the amount and intensity of $\alpha$ peaks of $900{ }^{\circ} \mathrm{C} / 30 \%$ specimen are obviously more and higher than $900{ }^{\circ} \mathrm{C} / 70 \%$ specimen. It can be deduced from these results that, the deformation is dominated by DRV at $900^{\circ} \mathrm{C}$, and the higher deformation degree can promote DRV, dynamic $\alpha$ precipitation and the $\alpha \rightarrow \beta$ phase transformation.

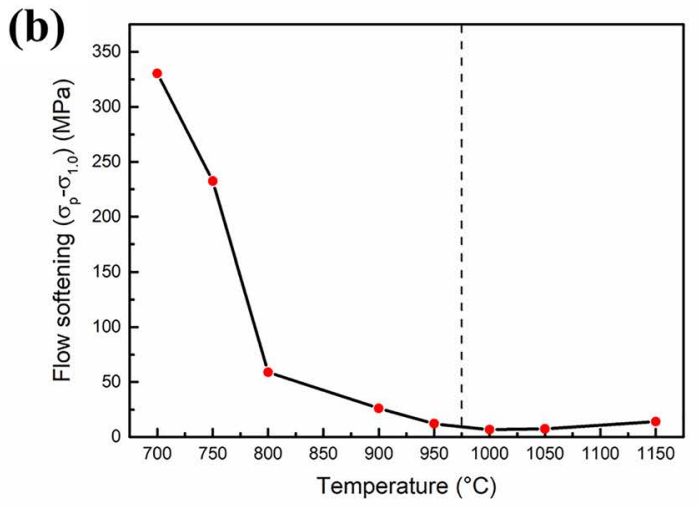

Figure 3. The changing of peak flow stress and flow softening values of as-consolidated PM Ti-5553 alloy with temperature of during hot deformation: (a) peak flow stress; and (b) flow softening $\left(\sigma_{\mathrm{p}}-\sigma_{1.0}\right)$ value 

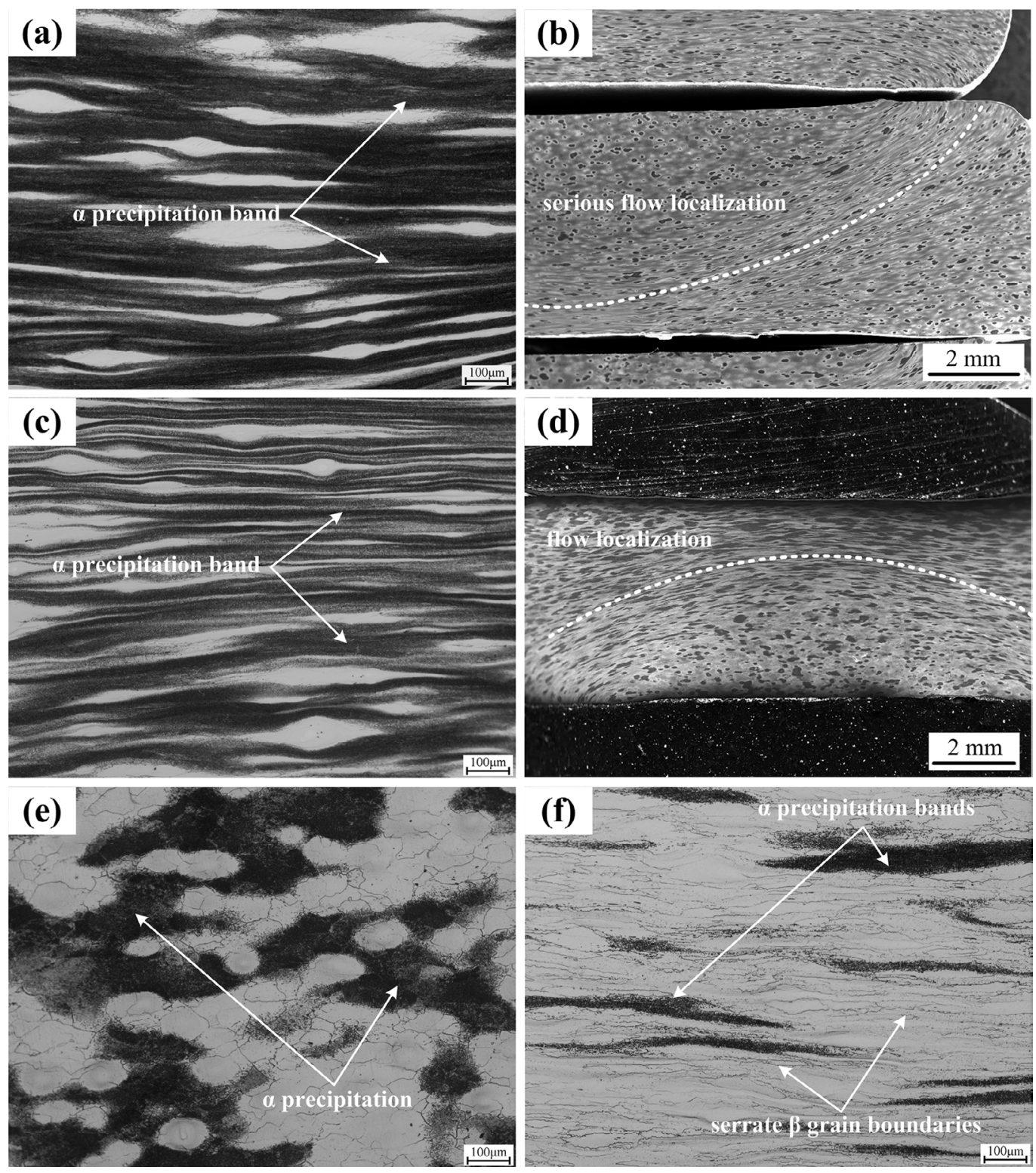

Figure 4. Optical microstructures and SEM characteristics of deformed PM Ti-5553 alloy subjected to various temperatures and deformation strain at $1 \mathrm{~s}^{-1}$ in $(\alpha+\beta)$ region: (a) OM, $700{ }^{\circ} \mathrm{C}, 70 \%$; (b) SEM, $700{ }^{\circ} \mathrm{C}, 70 \%$; (c) OM, $800{ }^{\circ} \mathrm{C}, 70 \%$; (d) SEM, $800{ }^{\circ} \mathrm{C}, 70 \%$; (e) $\mathrm{OM}, 900{ }^{\circ} \mathrm{C}, 30 \%$; and (f) $\mathrm{OM}, 900{ }^{\circ} \mathrm{C}, 70 \%$

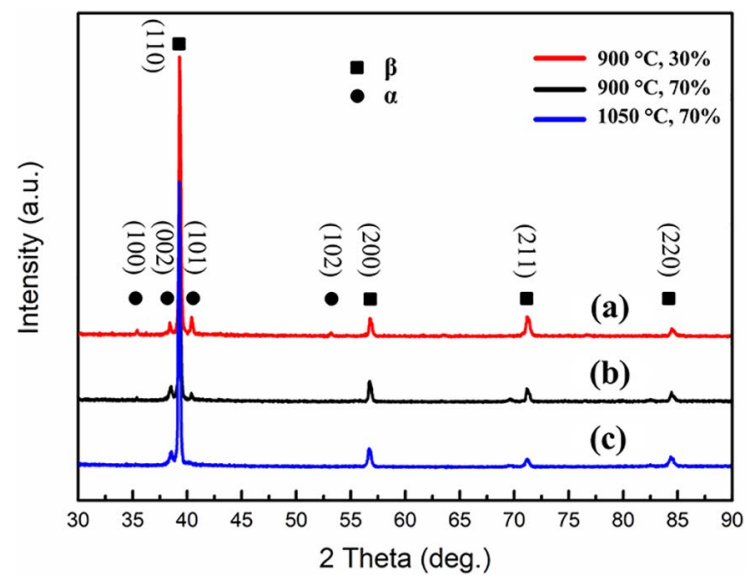

Figure 5. XRD patterns of deformed PM Ti-5553 alloy subjected to various temperatures and deformation degrees at $1 \mathrm{~s}^{-1}:$ (a) $900{ }^{\circ} \mathrm{C}$, $30 \%$; (b) $900{ }^{\circ} \mathrm{C}, 70 \%$; and (c) $1050{ }^{\circ} \mathrm{C}, 70 \%$

\subsection{Microstructure evolution near $\beta$ transus and at $\beta$ region}

Fig. 6 shows the optical microstructures of deformed PM Ti-5553 alloy subjected to various temperatures and strain at $1 \mathrm{~s}^{-1}$ from $950{ }^{\circ} \mathrm{C}$ to $1100^{\circ} \mathrm{C}$. As can be identified in Fig. $6 \mathrm{a}$ of $950{ }^{\circ} \mathrm{C}$ specimen, serrate grain boundaries dressed by distinct neck-lace shaped small grains can be easily observed, which reveals the flow softening mechanism is dominated by the combination of DRV and DRX. As the temperature increase to $1000{ }^{\circ} \mathrm{C}$ (Fig. 6b), the grain boundaries become more and more irregular and the size of recrystallized uniaxial grains become more and more large, indicating the enhancement of the DRX and DRV processes. When the deformation is processed at $1050{ }^{\circ} \mathrm{C}$ (Fig. 6e), fewer DRX grains are found, and the strong DRV process 

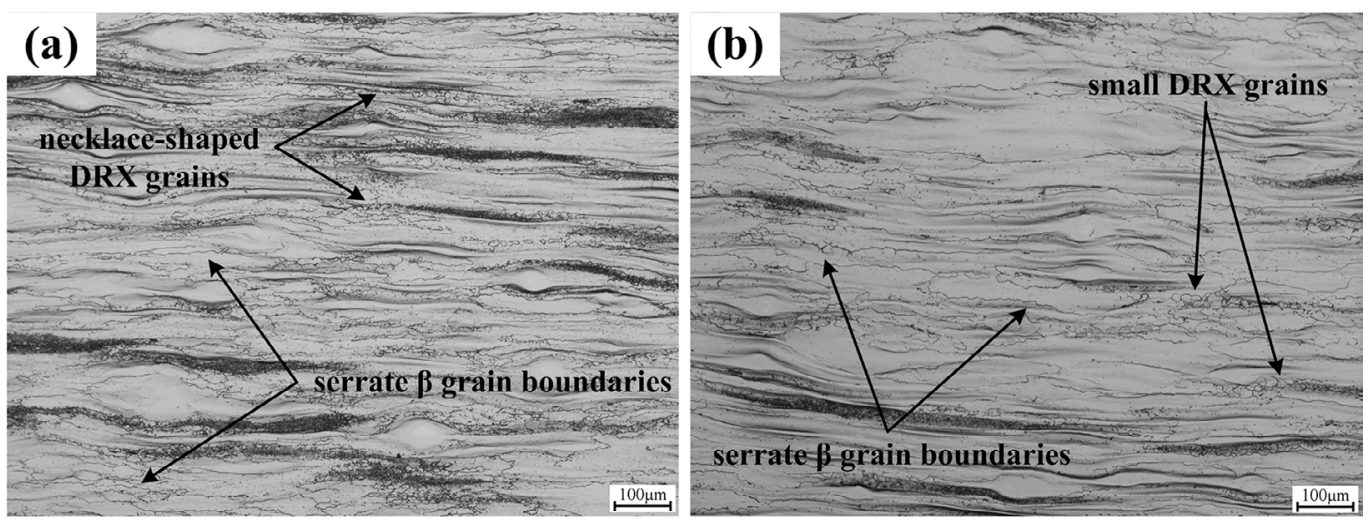

(c)

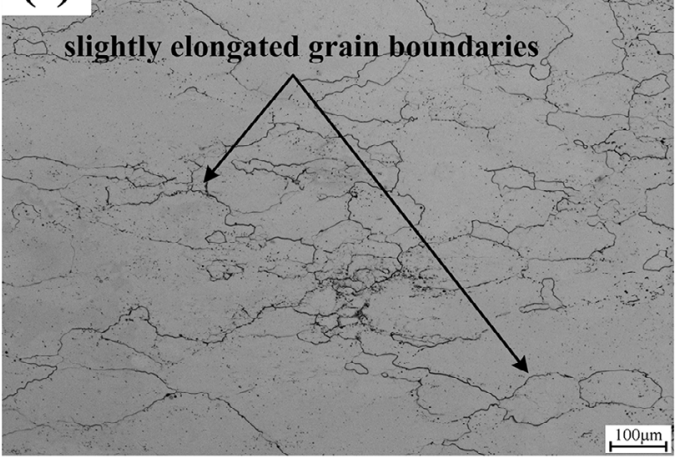

(d)
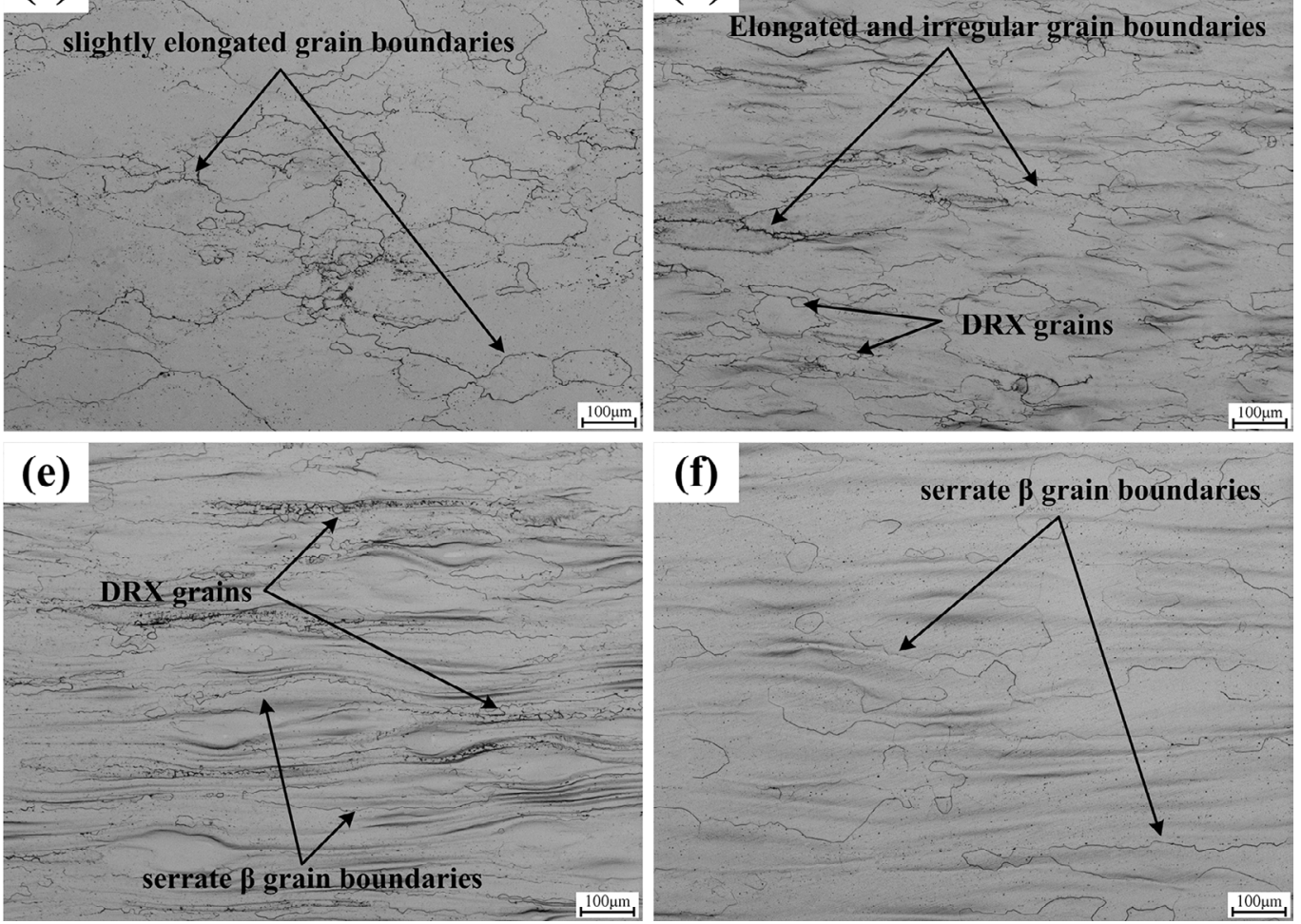

Figure 6. Optical microstructures of deformed PM Ti-5553 alloy subjected to various temperatures and deformation strain at $1 \mathrm{~s}^{-1}$ near the $\beta$ transus and in $\beta$ region: (a) $950{ }^{\circ} \mathrm{C}, 70 \%$; (b) $1000{ }^{\circ} \mathrm{C}, 70 \%$; (c) $1050{ }^{\circ} \mathrm{C}, 30 \%$; (d) $1050{ }^{\circ} \mathrm{C}, 50 \%$; (e) $1050{ }^{\circ} \mathrm{C}$, $70 \%$; and (f) $1150{ }^{\circ} \mathrm{C}, 70 \%$.

is still significant as the coarsening of the serrate grain boundaries. As the deformation temperature further increases to $1150{ }^{\circ} \mathrm{C}$ (Fig. 6f), no DRX grains but only the coarsen serrate grain boundary can be identified. Deformation degree also plays a significant role in determining the flow softening mechanisms. Fig. $6 \mathrm{c}$ and $\mathrm{d}$ show the microstructures of the specimen deformed at $1050{ }^{\circ} \mathrm{C}$ for the various deformation degree of $30 \%$ and $50 \%$. The grains are slightly elongated and keep straight for $30 \%$ height reduction specimen, while the obvious elongated grains with irregular grain boundaries and some small equiaxial DRX grains can be seen for $50 \%$ height reduction specimen.
These observation results reveal the DRV process is always remarkable at quite a wide temperature between $900^{\circ} \mathrm{C}$ and $1150^{\circ} \mathrm{C}$ range and occurrence of DRX process is prominent at the temperature range of $950{ }^{\circ} \mathrm{C}$ to $1000^{\circ} \mathrm{C}$ at this moderate high strain rate of $1 \mathrm{~s}^{-1}$. DRX is a thermal active process controlled by the elemental diffusion and can be facilitated by the elevated temperature. However, the high stacking fault energy (SFE) of titanium alloys make it easier for the dislocation to climb and gliding, which hinder the proceeding of DRX at high temperature over $1050{ }^{\circ} \mathrm{C}^{12}$. Meanwhile, the deformation can encourage DRV and DRX processes as these softening mechanisms 
are driven by the deformation stored energy and rely on the dislocation movement which can be higher and more active at a high deformation degree.

In terms of the situation of the dynamic $\alpha$ precipitation, as it can be seen in Fig. 6 , the amount of $\alpha$ precipitation shows an obvious tendency that it reduces with increasing the temperature, and the precipitate almost disappears at $1050^{\circ} \mathrm{C}$. As shown in Fig. $5 \mathrm{c}$, the XRD pattern of $1050^{\circ} \mathrm{C}$ specimen almost shows only $\beta$ peaks with high intensities, which means most of the $\alpha$ precipitates are dissloved and transformed into $\beta$ matrix at this condition. These observations indicate that dynamic $\alpha$ precipitation is only prominent during the processing of the PM Ti-5553 in $(\alpha+\beta)$ region and the region near $\beta$ transus, attribute to the $\alpha \rightarrow \beta$ phase transformation.

\section{Conclusions}

This work investigated the hot deformation behaviour of the PM Ti-5553 alloy at a moderate-high strain rate of $1 \mathrm{~s}^{-1}$ and a wide temperature range from $700{ }^{\circ} \mathrm{C}$ to $1150{ }^{\circ} \mathrm{C}$. Flow behaviour and microstructural evolution of during the deformation are studied and characterized clearly. Based on the results, the main conclusions can be obtained as:

1. The flow stress of the PM Ti-5553 alloy decreases with the increasing deformation temperature and flow softening phenomenon is more obvious at low temperature than at high temperature.

2. Flow localization is the dominated softening mechanism in the low-temperature range deformation of $700{ }^{\circ} \mathrm{C} \sim 800^{\circ} \mathrm{C}$, and the degree of the unstable deformation increases with reducing the temperature.

3. DRX mainly occurs at the temperature range of $950{ }^{\circ} \mathrm{C}$ to $1000^{\circ} \mathrm{C}$, while DRV occurs at a wider temperature range from $900^{\circ} \mathrm{C}$ to $1150^{\circ} \mathrm{C}$. Higher deformation degree can promote DRX and DRV processes, and obvious DRX and DRV features are observed in the deformation higher than $50 \%$ at elevated temperatures.

4. Dynamic $\alpha$ precipitation is prominent during the hot working of the PM Ti-5553 alloy in $(\alpha+\beta)$ region and the region near $\beta$ transus, which can also be enhanced by increasing the deformation degree.

\section{Acknowledgements}

The funding and support from New Zealand Ministry of Business, Innovation and Employment (MBIE, UOWX1402) are acknowledged gratefully.

\section{References}

1. Fanning JC. Properties of TIMETAL 555 (Ti-5Al-5Mo-5V-3Cr0.6Fe). Journal of Materials Engineering and Performance. 2005;14(6):788-791.
2. Jones NG, Dashwood RJ, Jackson M, Dye D. B Phase decomposition in Ti-5Al-5Mo-5V-3Cr. Acta Materialia. 2009;57(13):3830-3839.

3. Jones NG, Dashwood RJ, Dye D, Jackson M. The Flow Behavior and Microstructural Evolution of Ti-5Al-5Mo-5V-3Cr during Subtransus Isothermal Forging. Metallurgical and Materials Transactions A. 2009;40(8):1944-1954.

4. Hua K, Xue XY, Kou HC, Fan JK, Tang B, Li JS. High temperature deformation behaviour of Ti-5Al-5Mo-5V-3Cr during thermomechanical processing. Materials Research Innovations. 2014;18(Suppl 4):S4-202-206

5. Bolzoni L, Ruiz-Navas EM, Gordo E. Quantifying the properties of low-cost powder metallurgy titanium alloys. Materials Science and Engineering: A. 2017;687:47-53.

6. Bolzoni L, Ruiz-Navas EM, Gordo E. Evaluation of the mechanical properties of powder metallurgy Ti-6Al-7Nb alloy. Journal of Mechanical Behaviour Biomedical Materials. 2017;67:110-116.

7. Yang F, Raynova S, Singh A, Zhao Q, Romero C, Bolzoni L. Producing High-Quality Titanium Alloy by a Cost-Effective Route Combining Fast Heating and Hot Processing. JOM. 2018;70(5):632-637.

8. Singh AP, Yang F, Torrens R, Gabbitas B. Solution treatment of Ti-6Al-4V alloy produced by consolidating blended powder mixture using a powder compact extrusion route. Materials Science and Engineering: A. 2018;712:157-165.

9. Matsumoto H, Kitamura M, Li Y, Koizumi Y, Chiba A. Hot forging characteristic of Ti-5 Al-5V-5Mo-3Cr alloy with single metastable $\beta$ microstructure. Materials Science and Engineering: A. 2014;611:337-344.

10. Warchomicka F, Poletti C, Stockinger M. Study of the hot deformation behaviour in Ti-5Al-5Mo-5V-3Cr-1Zr. Materials Science and Engineering: A. 2011;528(28):8277-8285.

11. Seshacharyulu T, Medeiros SC, Frazier WG, Prasad YVRK. Microstructural mechanisms during hot working of commercial grade Ti-6Al-4V with lamellar starting structure. Materials Science and Engineering: A. 2002;325(1-2):112-125.

12. Fan JK, Kou HC, Lai MJ, Tang B, Chang H, Li JS. Characterization of hot deformation behavior of a new near beta titanium alloy: Ti-7333. Materials \& Design. 2013;49:945-952.

13. Zhu YC, Zeng WD, Zhao YQ, Shu Y, Zhang XM. Effect of processing parameters on hot deformation behavior and microstructural evolution during hot compression of Ti40 titanium alloy. Materials Science and Engineering: A . 2012;522:384-391.

14. Bai XF, Zhao YQ, Zeng WD, Jia ZQ, Zhang YS. Characterization of hot deformation behavior of a biomedical titanium alloy TLM. Materials Science and Engineering: A. 2014;598:236243.

15. Peng WW, Zeng WD, Wang QJ, Yu HG. Characterization of high-temperature deformation behavior of as-cast Ti60 titanium alloy using processing map. Materials Science and Engineering: A. 2013;571:116-112.

16. Liu SF, Li MQ, Luo J, Yang Z. Deformation behavior in the isothermal compression of Ti-5Al-5Mo-5V-1Cr-1Fe alloy. Materials Science and Engineering: A. 2014;589:15-22. 